\title{
Literatura e quadrinhos: adaptações de Edgar Allan Poe
}

\section{Literature and Comic Books: Adaptations of Edgar Allan Poe}

\author{
Fernando da Silva
}

\begin{abstract}
Resumo: Em vista do atual reconhecimento das histórias em quadrinhos (HQs) como um fenômeno de mídia de massa e de expansão da literatura, este artigo tem por objetivo lançar um olhar aproximado à forma como imagem e texto são intercambiáveis em HQs como formas de representação aos sentidos e significados em algumas obras adaptadas do autor Edgar Allan Poe para este formato. Para tanto, neste texto serão observadas algumas adaptações em formato quadrinizado da obra do autor mencionado considerando o seu valor estético e de reinterpretação do texto literário. As análises que remetem às releituras da obra de Poe indicam nas retextualizações em formato de HQs não apenas a materialização do texto em imagens a partir de sistemas semióticos distintos, como é próprio do gênero textual história em quadrinho, mas também uma reorientação espaço-temporal das histórias apresentadas.
\end{abstract}

Palavras-chave: História em quadrinhos (HQs); retextualização; literatura

Abstract: In the light of the recent emergence of Comic Books as a mass media phenomena and of popularization of literature, this article aims at providing a deep look of introspection on how the investigation of comic books, as form of literary text adaptation, provides important insights to the way image and text are interchangeable as a means to represent meaning and senses in the works of Edgar Allan Poe. Thus, in this text a few short stories by the aforementioned author, and adapted to the comic book format, will be observed by taking into account their aesthetic value and their retextualization as literary texts. The analyzes that operate within the works of Edgar Allan Poe indicate that in the retextualizations in comic book format there is not only the materialization of text into images from distinct 
DA SILVA, F. - Literatura e quadrinhos - adaptações de Edgar Allan Poe

semiotic systems, as it is characteristic of the text genre, but also, a reorientation in terms of space and temporality in the stories investigated.

Keywords: Comic book stories; retextualization; literature

Com constância podemos achar disponíveis adaptações literárias que chegam ao mercado com a proposta de trazer a um novo público, em sua maioria mais jovem, ainda que não regra, textos literários adaptados para o formato de histórias em quadrinhos (doravante HQ). Estas adaptações não só estendem a sua influência dentro de seu próprio domínio de distribuição, a literatura, mas também potencializam a criação de novas formas de representação artística a partir da literatura.

De acordo com Mendonça (2010), um dos primeiros movimentos de adaptação literária, e talvez de didatização da literatura, iniciou-se nos EUA na década de 40, através da publicação de várias antologias sobre personagens clássicos da literatura e acontecimentos históricos marcantes que dialogavam entre si a partir de uma obra única no formato $H Q$. Ainda, segundo a autora, na primeira metade do século XX, entre 1941 e 1971, é lançada nos EUA a coleção de clássicos da literatura adaptados para o formato de HQ, Classics llustrated. Servindo de inspiração a outras publicações de mesmo formato que viriam a seguir, licenciadas sob a mesma marca ou não, esta coleção, a partir de seu lançamento, motivou no Brasil todo um movimento de tradução e adaptação de obras literárias clássicas.

Hoje, a arte sequencial, como são referidas HQ por MacCloud (2012), ainda encontra-se em uma busca constante de legitimação literária. Todavia, é preciso questionar a razão de tal fenômeno se fortalecer apenas dentro de um momento específico, uma vez que a arte pictórica, a narrativa atribuída à imagem, é uma ou talvez a mais antiga forma de representação de significados que temos registro, segundo MacCloud. É importante notar que esta manifestação artística não representa apenas hoje uma forma de esforço 
DA SILVA, F. - Literatura e quadrinhos - adaptações de Edgar Allan Poe

institucional para tornar a literatura, o texto, mais acessível às chamadas massas, mas constitui-se como uma continuidade de uma forma de representação de informação, narrativas, história, e, sobretudo, artística, que se faz presente desde a cultura pré-escrita segundo o autor supracitado.

De maneira análoga ao processo de adaptação literária para o cinema, apenas como contraponto, o processo de transposição do textual para o visual, como é no caso de obras quadrinizadas, em muitos casos, está atrelado a uma relação de submissão estilística e estética com a obra a que se propõe adaptar. Cortes, elipses de tempo, montagens paralelas são todos recursos de cinema utilizados pelos quadrinhos, porém a partir de imagens estáticas. Enquanto a imagem do cinema apresenta movimento, o quadrinho sugere e simula uma progressão através de códigos pictóricos inerentes ao seu gênero. Todavia, é possível considerar que nem mesmo no cinema há um movimento real, uma vez que este movimento é apenas uma ilusão provocada pela velocidade das imagens imposta pela mecânica, pela mediação da câmera na filmagem e do projetor na exibição (MUANIS 2006).

\begin{abstract}
A função fundamental da arte dos quadrinhos (tira ou revista), que é comunicar ideias e/ou histórias por meio de palavras e figuras, envolve o movimento de certas imagens (tais como pessoas e coisas) no espaço. Para lidar com a captura ou encapsulamento desses eventos no fluxo da narrativa, eles devem ser decompostos em segmentos sequenciados. Esses segmentos são chamados quadrinhos. Eles não correspondem exatamente aos quadros cinematográficos. São parte do processo criativo, mais do que um resultado da tecnologia (EISNER 1989: 38).
\end{abstract}

Nesta forma de representação narrativa, segundo Costa (2009), sua estrutura se assemelha de maneira coesa à narrativa cinematográfica.

[...] Por ser o pictograma ou a vinheta a unidade narrativa da HQ e por ser o objeto de elaboração e dinamização de narrativas inspirado no cinema, com enquadramentos, planos, ângulos de focagem, cromatismos, etc, a sucessividade dos pictogramas e textos dá um dinamismo e um ritmo particulares à ação, às elipses 
(que separam os pictogramas) de eventos implícitos interligam os fatos por uma articulação de duas ou mais ações em paralelo (pp. 128 , grifos do autor).

Estes aspectos de sequenciamento, códigos circunscritos a este gênero textual, materializam-se no que diferentes autores conceituam como uma gramática visual, que de forma semelhante à sua contraparte linguística estrutura o processo de interpretação de experiências a partir de comunicação visual através de recursos imagéticos. Na HQ, um sistema de orientação se constitui no texto visual através de um vetor que estabelece o caminho da narrativa entre as imagens. Esta linha imaginária de orientação narrativa representa o desdobrar de ações, eventos, mudanças de processos, reorganização de espaços transitórios, mostrando que um enquadramento, uma imagem, ou um aspecto desta, está conectado a uma textualidade (KRESS \& VAN LeEuWEn 2006).

Para Eisner (1989), na arte sequencial há uma constante sobreposição da palavra e da imagem. Aspectos relativos à regência da arte visual e literatura, tais como perspectiva, enquadramento, simetria, sintaxe, aspectos narrativos se fundem em um ato de percepção estética e estilística de ambos os lados. Paradoxalmente, a partir desta perspectiva do autor, nesta forma de expressão textual, o texto também pode desempenhar o papel da imagem de forma a criar, através de diferentes conformações visuais, pontes narrativas que remetem a diferentes sentidos imagéticos e estilo literário (fig.1). 
DA SILVA, F. - Literatura e quadrinhos - adaptações de Edgar Allan Poe

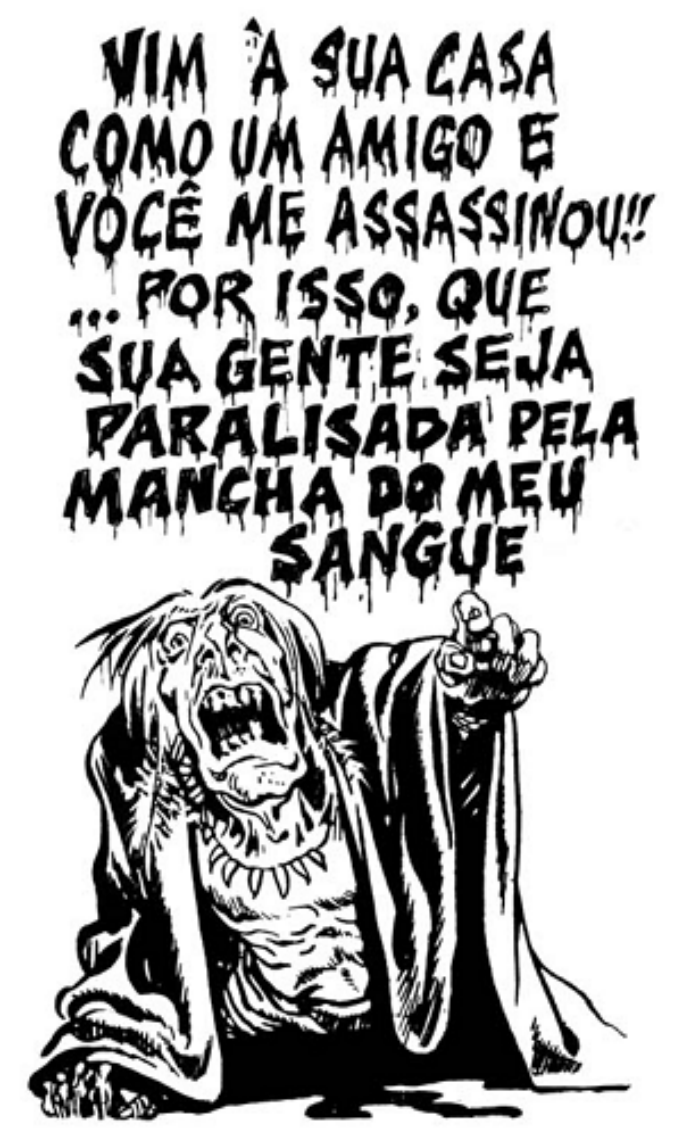

Figura1 (EISNER 1989: 12)

Na fig. 1, além de cumprir com sua função textual, as palavras têm a função de transferir para o leitor um valor de imagem e de uma atmosfera narrativa. Neste sistema existem pontos de contato onde a palavra e a imagem que se correlacionam de forma a compor uma mensagem. Estes lugares de intersecção se sustentam a partir do grau de colaboração entre o texto e o visual, que podem ser configurados através de aspectos de ordem aditiva, e paralelamente, de forma excludente ou independente, dependendo do ilustrador. Da mesma forma como ocorre no texto traduzido, obras adaptadas para a HQ revelam uma percepção do ilustrador acerca dos principais eventos que sustentam a narrativa no texto original. Temos então na HQ uma materialização visual de várias expressões de prioridades organizadas através de um único sentido, a visão (EISNER 1989). 
Todavia, o texto também pode ser utilizado de forma a adicionar uma dimensão sonora à imagem, inserindo no lugar de extensos segmentos descritivos, por exemplo, representações de onomatopeia, muito comuns em tal gênero, como ilustrado na figura 2, da adaptação do poema The Raven, por Corben e Margopoulos (2006), no primeiro volume da adaptação de Edgar Alan Poe's Haunt of horror. Estes artifícios, além de adicionar uma ideia de representação e sentidos ao texto e à imagem, muitas vezes não implementáveis em um artefato de representação unidimensional, como é o texto (através do texto), funcionam como pontes narrativas que sustentam um ritmo fluido do enredo com características multimodais (EISNER 1989). Ainda que seja perceptível uma relação de emulação de entremeios, em uma forma de representação para outra, no processo de adaptação do texto literário para o texto quadrinizado, temos uma constante ampliação de estética de conteúdos através de outros recursos que não apenas a literatura em uma sequência de imagens estáticas. Em outras palavras, dispositivos que oferecem à obra literária adaptada um dinamismo muito maior na representação de alguns aspectos de sua narrativa, sobretudo se considerarmos este movimento de transição como um processo de releitura no sentido tradutório.
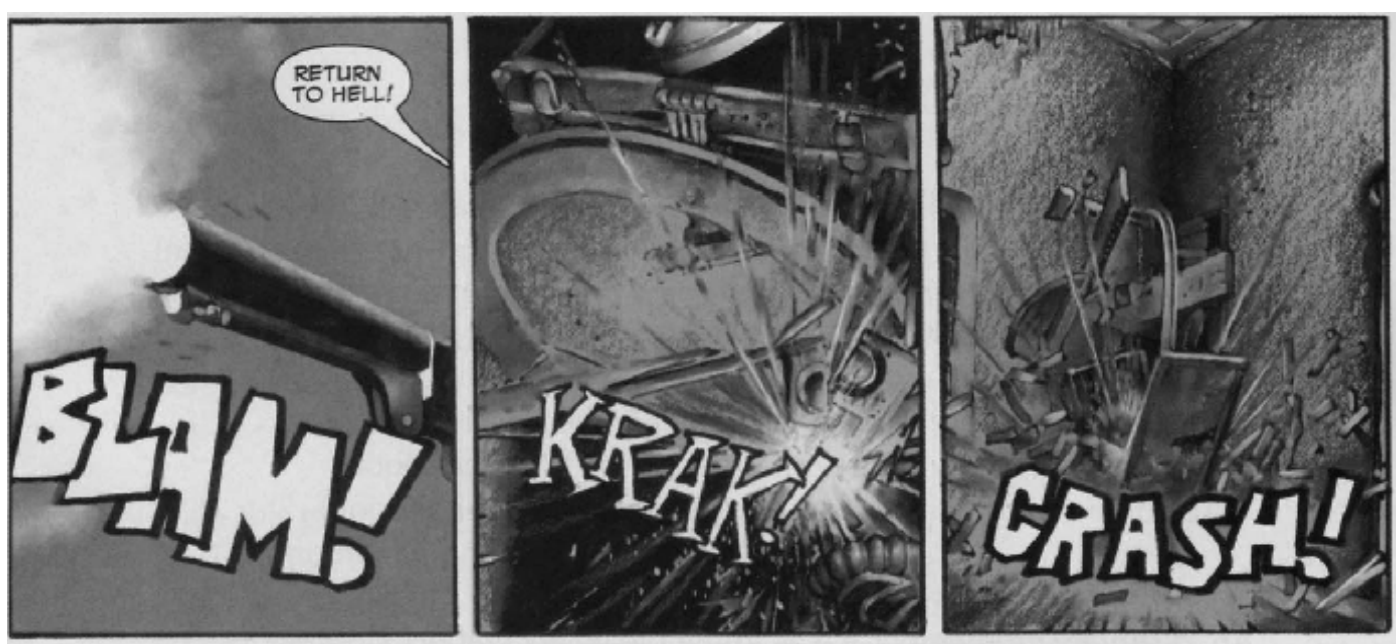

Figura 2 - The Raven (2006: 11) 
DA SILVA, F. - Literatura e quadrinhos - adaptações de Edgar Allan Poe

Para Muanis (2006), em HQs, o ângulo de posicionamento do que se configura como uma câmera imaginária assume um ponto de vista narrativo na história, e, da mesma forma como na literatura, posicionando seus personagens em um plano espaço-temporal. Este recurso amplia de maneira significativa algumas estratégias de perspectiva narrativa, tal como 0 posicionamento de um personagem como um protagonista em $1^{\text {a }}$ pessoa, em $3^{\text {a }}$ pessoa ou em um enquadramento panorâmico, como ilustrado na figura 3 , da adaptação do conto The Tell-tale Heart, por Corben e Margopoulos (2006), no primeiro volume da adaptação de Edgar Alan Poe's Haunt of horror. Muitas opções de enquadramento no texto quadrinizado também reforçam o caráter dinâmico de algumas narrativas, à medida que certos elementos de uma história ganham mais atenção, assim como um autor opta por utilizar diferentes estratégias textuais trazendo à tona aspectos relevantes da construção de um personagem, ou se este for o caso, da representação imagética de um lugar ou evento (MUANIS 2006). 
DA SILVA, F. - Literatura e quadrinhos - adaptações de Edgar Allan Poe

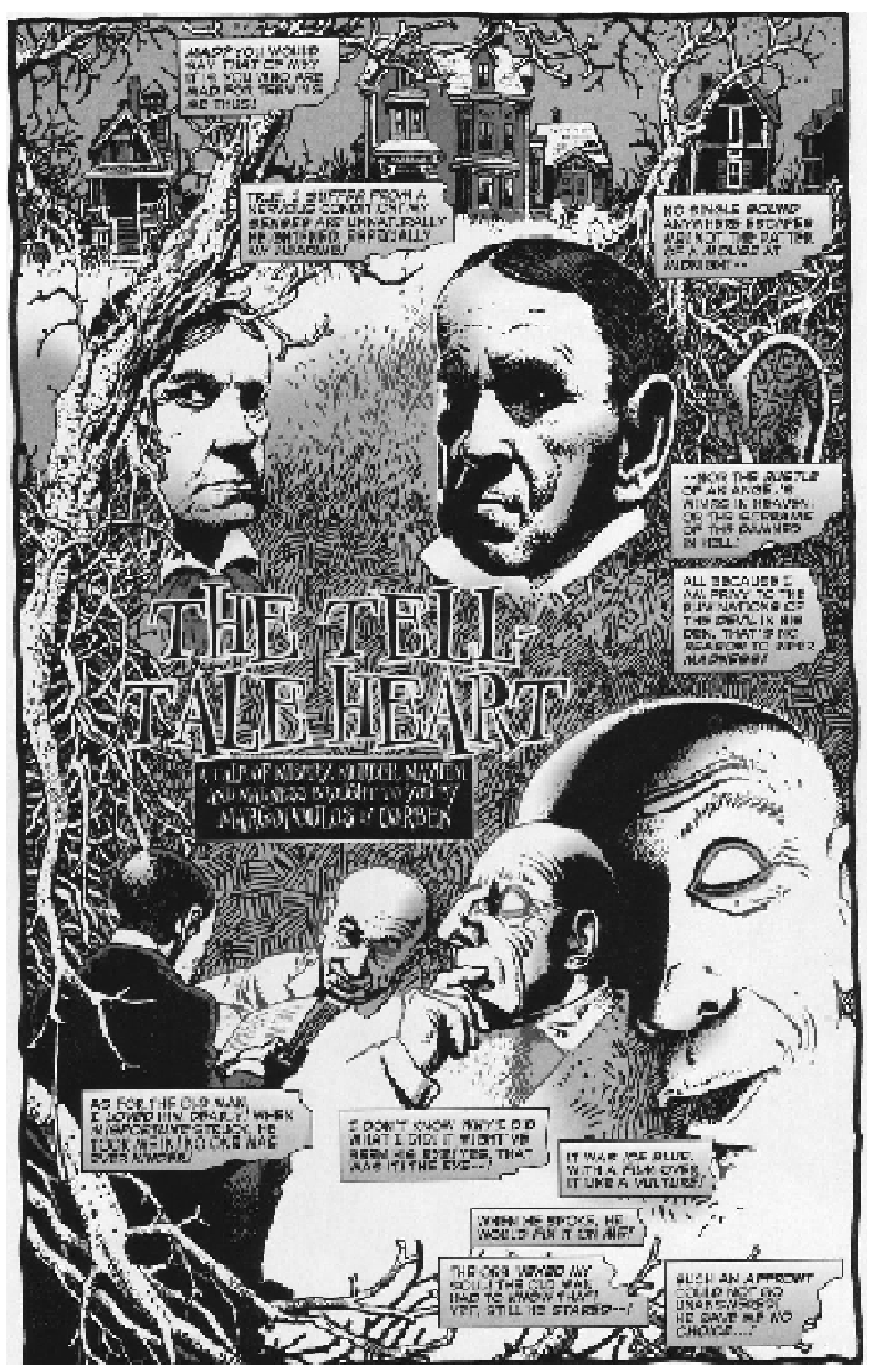

Figura 3 - The Tell-tale Heart (2006:1)

O processo de adaptação do texto literário para a arte sequencial não deve necessariamente se sustentar em uma transposição linear do conteúdo textual para a obra adaptada, mas sim ser compartilhado com a imagem de forma a estabelecer uma relação de completude do texto através de recursos imagéticos. De maneira semelhante ao processo de tradução, como se dá em sua forma tradicional onde pode haver uma relação clara de perdas e ganhos, se comparados o texto fonte e o texto alvo, na adaptação do literário para a HQ este fenômeno se torna igualmente perceptível. Neste processo de adaptação, é possível notar em muitos autores a tentativa de recriar a obra 
DA SILVA, F. - Literatura e quadrinhos - adaptações de Edgar Allan Poe

original, sobretudo se estes não estão presos a alguma clausula de propriedade editorial e autoral. De acordo com Caputo (2003 apud HIDAYAT E ZPALANZANI 2011) alguns aspectos importantes e devem ser contemplados no processo de adaptação de textos literários para HQ:

- Clareza na implementação de efeitos de sequenciamento, imagens e enquadramento na história contada. Todos os elementos presentes na história devem apresentar um propósito claro e dar pistas acerca da continuidade da narrativa.

- Realismo é o elemento fundamental de coesão da história. 0 aspecto de realismo emergirá através da consistência de elementos causais na história aplicados ainda que este realismo possa diferir do mundo real.

- Dinamismo: se refere à aplicação de gestos nos personagens e nas sequências visuais com o objetivo de criar um fluxo dinâmico ao invés de imagens fixas e imóveis. Este aspecto requer do quadrinista noções de ângulo de enquadramento, movimentação e dinamismo nos gestos dos personagens.

- Continuidade: se refere à aplicação de elementos de transição visual, tais como corte a corte ou cena a cena (tradução minha, pp. 42).

Em uma versão do conto The Fall of the House of Usher, ilustrado por Tom Sutton na revista americana Eerie (1969, pp.1), na primeira página da adaptação é possível observar uma longa sequência introdutória de textos e imagens. A partir de uma ampla configuração de imagens em plano aberto, o ilustrador inicia a descrição de um cenário que mais tarde se tornará um dos principais personagens no conto de Poe, a casa de Usher. Esta imagem em plano aberto, seguida por outras tantas durante a adaptação, além de surgirem como um recurso que favorece uma maior explicitação de aspectos de representação geográfica, funciona como forma de minimizar longos segmentos de descrição imagética presentes no texto literário original (fig. 4). Muitas das nomenclaturas utizadas para a interpretação deste tipo de 
representação imagética, tal qual a descrita acima, são intercambiáveis com formas de descrição e análise de meios dinâmicos, como cinema, animações, comumente utilizadas em campos teóricos de análise de filmografias e de multimodalidade.

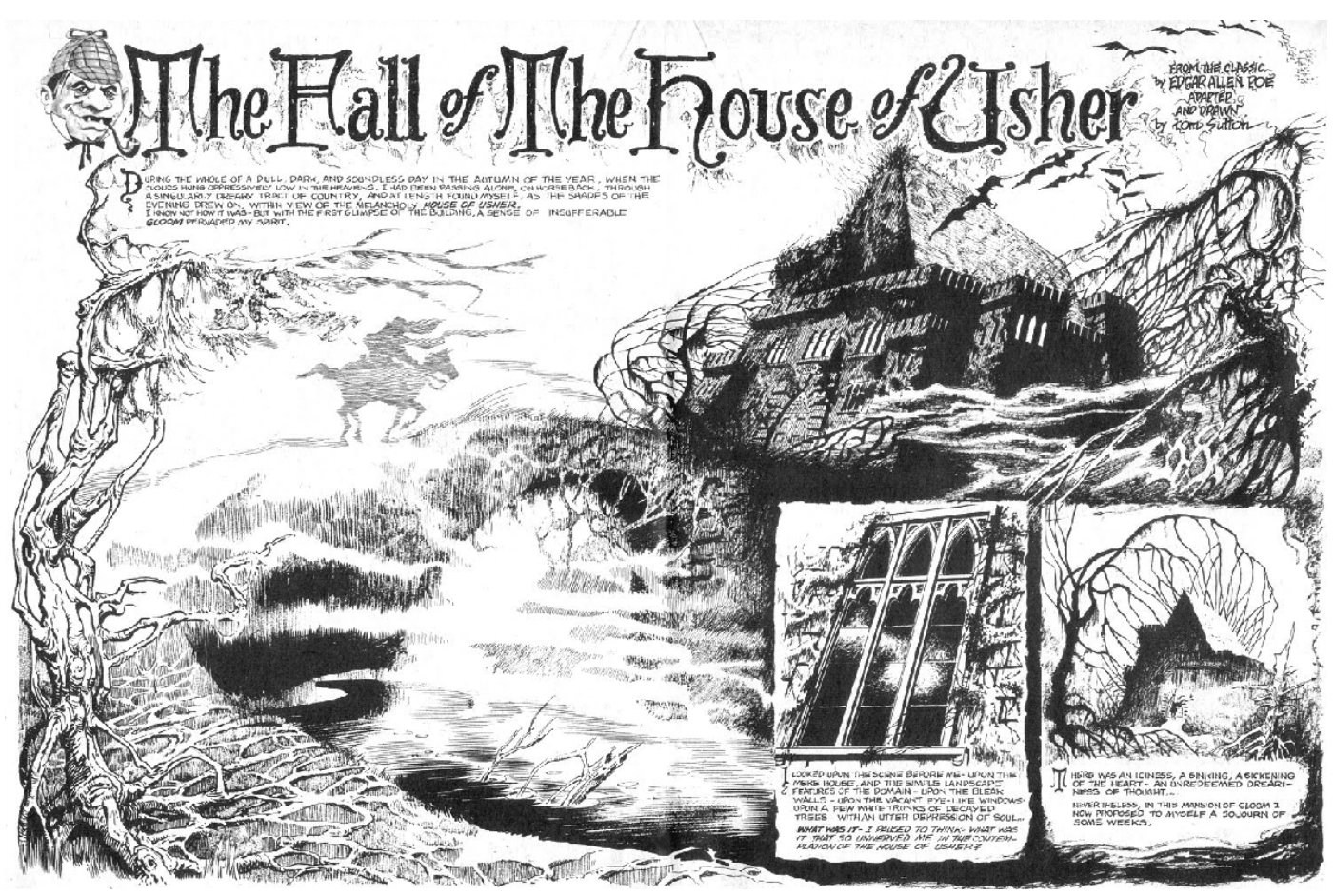

Figura 4 - The Fall of the House of Usher (1969, pp. 1)

Para McCloud (1995), na arte sequencial, a percepção do leitor constitui-se a partir do que o autor chama de um "ato de fé", o qual nos faz perceber o todo através das partes, isto é, da mesma forma que não precisamos, por exemplo, ir ao espaço para saber que a terra é redonda, no texto quadrinizado não é necessário uma representação integral de todos os elementos que constituem uma narrativa para que possamos compreendê-la por completo. Através de percepções e experiências anteriores, muitas vezes a partir de uma memória discursiva, é possível criar imagens mentais acerca dos mais diversos eventos dentro de uma história. Este fenômeno ganha o nome de sarjeta no texto em quadrinhos (fig. 5). Caracterizada como espaço 
DA SILVA, F. - Literatura e quadrinhos - adaptações de Edgar Allan Poe

entre dois enquadramentos, esta relação configura-se como uma espécie de omissão espaço-temporal que funciona como uma ponte narrativa imaginaria entre uma ideia e sua conclusão, entre o entendido e o que deve ser subentendido. É neste limbo que o autor, através da colaboração mutua do leitor, constitui sua intenção comunicativa e narrativa (MCCLOUD 2005).

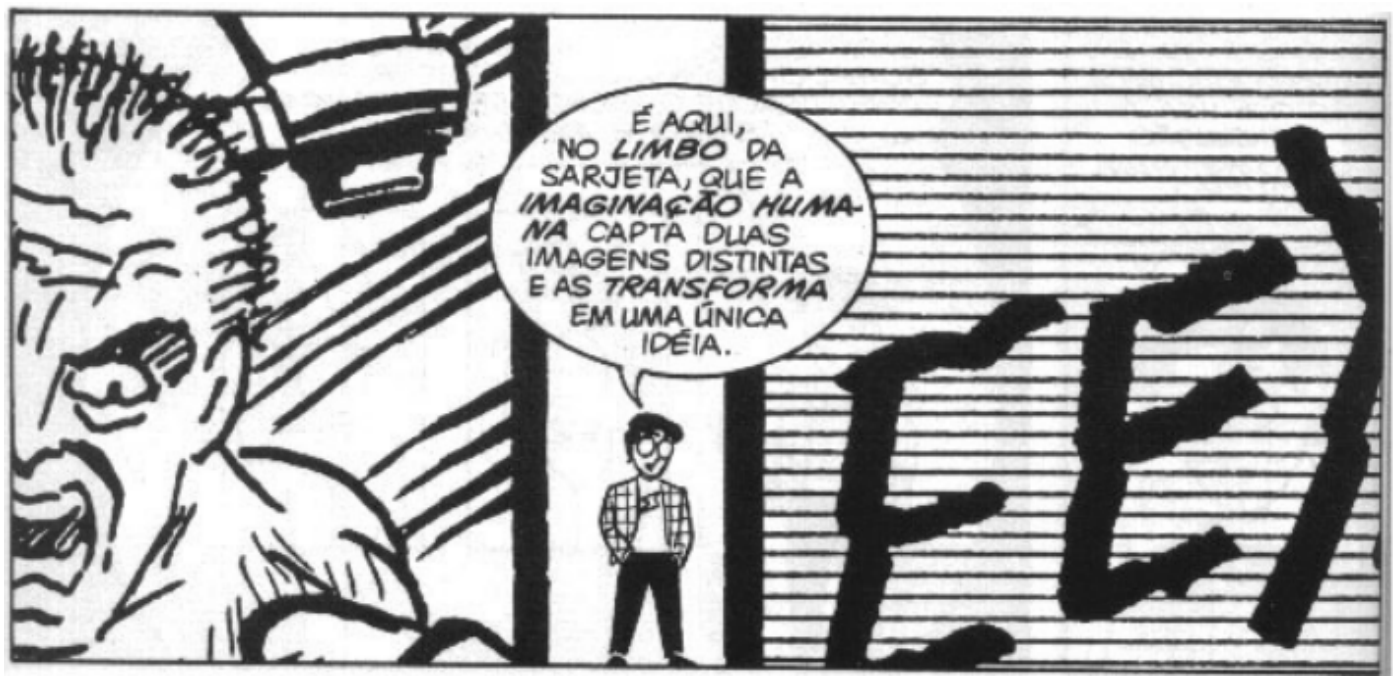

Figura 5 - McCloud (1993: 66)

Na figura 6 da adaptação The Tell-tale Heart (1965), de Crandall, é possível ver o quão ativa é esta função que, a partir de uma experiência prévia do autor, organiza uma sequência de imagens aparentemente descontinuadas em uma representação de um evento. Na leitura do texto quadrinizado esta tarefa torna-se um exercício ativo e contínuo por parte do leitor, que durante a sua leitura preenche os espaços vazios a partir de uma percepção de coesão e coerência textual (IBID). Este fenômeno, de acordo com McCloud (1995), cria um equilíbrio entre o que se vê e o que não se vê (como no texto, entre o dito e o não dito), através do que é oferecido ao leitor por meio do que é desenhado e o que deve ser imaginado neste interstício de imagens. Para Cirne (2000),

Quadrinhos são uma narrativa gráfico-visual impulsionada por sucessivos cortes, cortes estes que agenciam imagens rabiscadas, 
desenhadas e/ou pintadas. O lugar significativo do corte - que chamaremos de corte gráfico - será sempre o lugar de um corte espaço-temporal, a ser preenchido pelo imaginário do leitor. Eis aqui uma especificidade: o espaço de uma narrativa gráfica que se alimenta de cortes igualmente gráficos (p. 23).

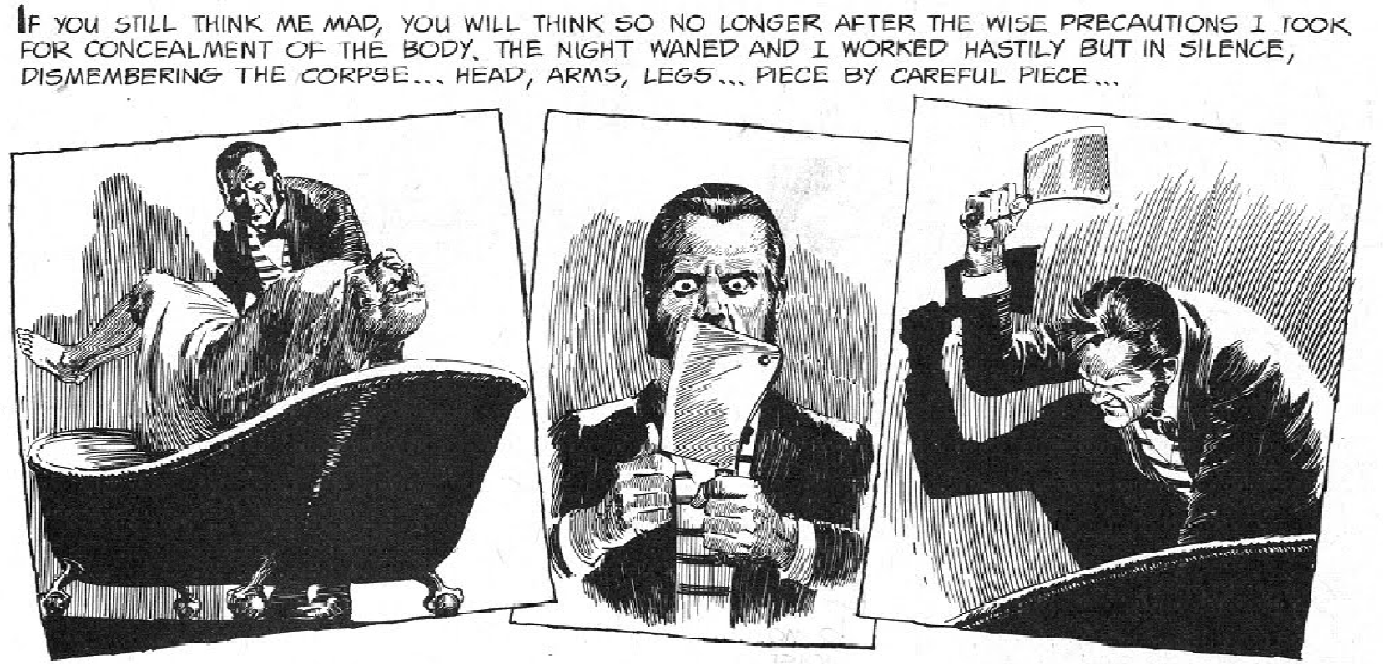

Figura 6 - The Tell-tale Heart (1965, p.5)

De forma análoga ao texto traduzido, no texto quadrinizado, a influência do ilustrador se faz igualmente presente e se torna proporcionalmente notável através de seus traços, das escolhas de enquadramento, de forma semelhante ao que se constituem como decisões tradutórias. Semelhante ao que ocorre em uma tradução, o quadrinista, se não preso às limitações de um contrato ou uma pauta de criação na forma de um roteiro prévio, como supracitado, pode optar por estender seu trabalho de criação na forma de um texto/conjunto de imagens redimensionado a partir de seus próprios critérios artísticos e estéticos. Para Pereira (2008),

[...] as metodologias implementadas por ilustradores são na maioria dos casos as mesmas que utilizadas por tradutores durante a tradução de textos. Como produtos, ilustrações desempenham um papel significativo na recepção de uma obra literária, ao ponto que a criação visual de um desenho seja muito similar à criação verbal de um texto durante a tradução. [...] (pp. 105). 
DA SILVA, F. - Literatura e quadrinhos - adaptações de Edgar Allan Poe

Talvez um dos autores mais extensivamente adaptados para esta forma de representação de arte contemporânea tenha sido Edgar Allan Poe. Seus contos e poemas distinguem-se por uma estética particular, que confere ao seu texto uma noção de tempo e desdobramento de trama própria dentro de sua narrativa. Uma das características mais presentes no processo de tradução gráfica das obras de Poe para os quadrinhos, nas obras observadas para a composição deste artigo, é a tentativa de fazer uma aproximação estética com sua obra original, mesmo que através de uma licença poética, que não remeta a uma transposição literal de seus poemas e contos (ROYAL 2008).

É possível perceber em algumas das primeiras adaptações de seus escritos um realismo maior, seja em termos estéticos ou de verossimilhança visual. Um exemplo são as tiragens da revista em quadrinhos americana Creepy (1965), ilustrada por Reed Crandall, suas edições tentam mimetizar quase todos os aspectos narrativos e descritivos dos contos que se propõem a adaptar. Algumas das primeiras releituras de sua obra são ilustradas de forma a reproduzir o estilo de seus contos, refletindo os aspectos geográficos e temporais inerentes às suas narrativas originais. Por se tratarem de obras transpostas em quase sua literalidade, acrescidas de ilustrações, o desafio de leitura de certa forma é facilitado através do recurso imagético com suporte textual, tornando estas adaptações quase que versões ilustradas de seus textos originais (IBID).

Ainda que haja toda uma extensa construção visual dos contos e poemas em algumas versões mais antigas de adaptações em formato $H Q$, também se torna evidente aos olhos em um primeiro momento um suporte textual expandido dos diálogos (fig. 7). Uma das características que se sobressaem em algumas das versões observadas, são as falas de personagens dentro dos balões que não apenas representam enunciados breves, característica própria do gênero $\mathrm{HQ}$, mas constituem-se em sua maioria de parágrafos inteiros adaptados para uma linguagem mais acessível ao leitor.

Quanto a uma relação includente e excludente de conteúdos nos quadrinhos observados, há uma variação que emerge de forma a balancear 
DA SILVA, F. - Literatura e quadrinhos - adaptações de Edgar Allan Poe

uma estética de representação, sobretudo se visualizada à luz da obra de Poe. Torna-se claro que mesmo que o ilustrador decida por incorporar elementos à obra ilustrada que fujam de uma tradução literal, variando desde deslocamento histórico da trama original, ainda assim fica clara uma presença inequívoca do tom mórbido, característico de Edgar Allan Poe. Estes acréscimos, ou decréscimos, constituem-se de certa forma em uma tentativa de criar um caráter de independência da obra original, revelando uma percepção artística individual que conduz o leitor a uma interpretação quase que única de um processo de tradução visual (ROYAL 2008).

Algumas adaptações, como já antes mencionado, fogem do confinamento que muitos supõem ser criado através do texto original (parte de um dos grandes paradigmas da tradução), a partir do que se estabelece como uma relação tradutória de adaptação e recriação como no caso dos quadrinhos. A partir dos exemplos observados, parece válido afirmar que em tais adaptações há de forma genuína uma preocupação em se preservar uma intenção comunicativa do autor, ou ainda o que se constitui como a estética de sua obra. Desta forma, fazendo um paralelismo entre a quadrinização de obras literárias e o processo tradutório, observa-se no texto quadrinizado uma aproximação dinâmica de sentidos e conteúdos. Este direcionamento se constitui a partir do alinhamento do tradutor/ilustrador/quadrinista com as convenções estéticas da obra adaptada e do gênero que se propõe a reproduzir.

Outro ponto a ser abordado é o fato de haver uma explicitação maior do enredo, característica compartilhada na maioria das vezes por textos traduzidos, e neste caso por uma decisão do ilustrador. Alguns elementos textuais dão suporte a esta característica, facilitando uma melhor compreensão da história, como por exemplo, a nominalização de personagens, pistas de contextualização textual que marcam a passagem de tempo e localização dos personagens dentro da trama, características tipográficas, 
DA SILVA, F. - Literatura e quadrinhos - adaptações de Edgar Allan Poe

elementos estes que facilitam uma leitura inferencial e avaliativa da obra, como pressupõe o gênero HQ, como na figura 7, ilustrada por Crandall (1965).

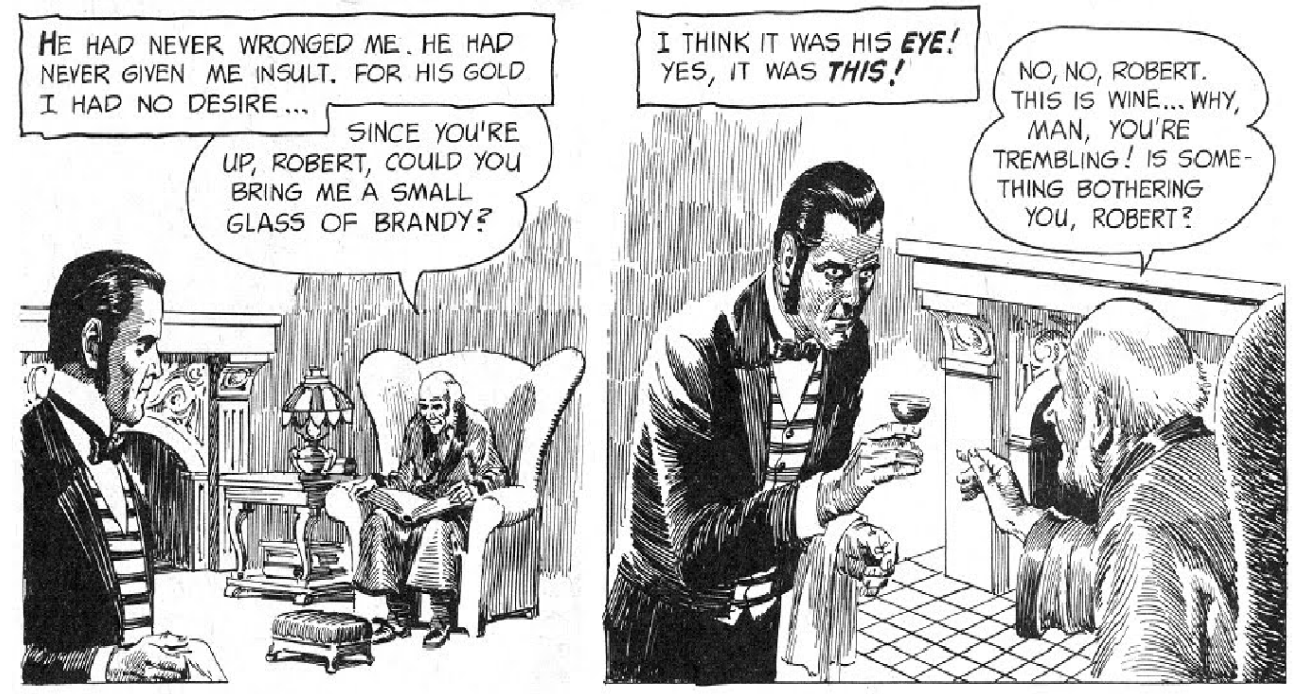

Figura 7 - The Tell-tale Heart (1965, p. 2)

Algumas traduções/releituras, como é o caso das tiragens Haunt of Horror (2006), da editora Marvel, destacam-se por meio de uma manutenção maior de registro na fala de seus personagens, ainda que nessas edições haja uma releitura deslocada entre a obra original e o texto quadrinizado em termos espaço-temporais. Estas edições expandem sua narrativa original ao propor finais alternativos, perturbadores e irônicos como na obra de Poe (ROYAL 2008). Outro ponto de destaque em uma das adaptações observadas é a não obrigatoriedade ao formato de $\mathrm{HQs}$ tradicionais com espaços compartimentados, isto é, enquadramentos separados dentro de uma mesma página (fig. 8). Em uma adaptação de 2006 do conto The Tell-tale Heart, ilustrado por Corben e Margopoulos, onde muitos segmentos são contados a partir de imagens únicas, de imagens sobrepostas em um plano aberto, remetendo a todo o momento o caráter de uma narrativa contada, lembrada, por um narrador onisciente. 
DA SILVA, F. - Literatura e quadrinhos - adaptações de Edgar Allan Poe

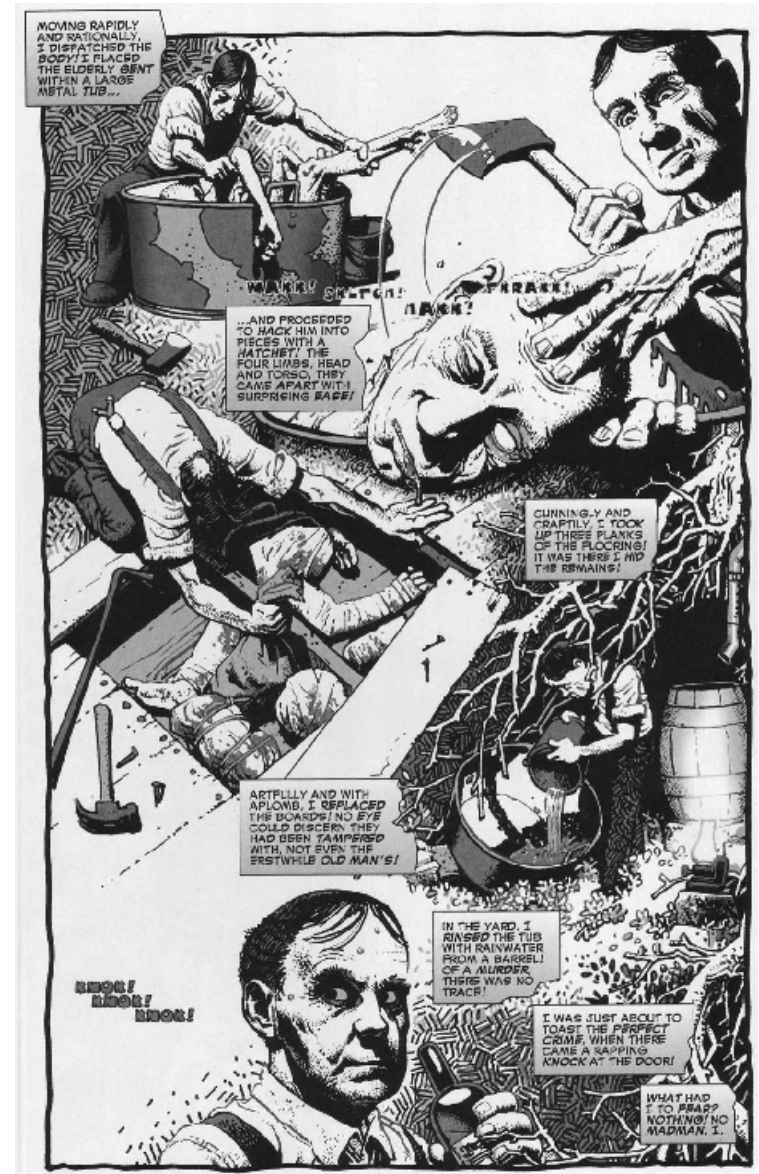

Figura 8 - The Tell-tale Heart (2006, p. 3)

Ainda que em muitos casos os textos adaptados possam diferir em muito de suas fontes originais, a relação estabelecida entre estas duas formas de representação, literária e imagética, contribui para um melhor entendimento de uma complexidade estética da imagem e da letra como instrumentos de construção narrativa como aponta Eisner (1989). A tradução das obras literárias por imagens, a leitura visual, remete ao leitor a formação de uma consciência acerca dos aspectos que representam o gênero textual e seus elementos de constituição estética. 
DA SILVA, F. - Literatura e quadrinhos - adaptações de Edgar Allan Poe

\section{Considerações finais}

O caráter reducionista e deformador da literatura, tipicamente associado a algumas retóricas que versam sobre o uso de HQs em reinterpretações literárias, não mais limita o texto quadrinizado ao confinamento de um espaço de dimensões reduzidas e simplificadas. Tampouco deve ser vista apenas como um instrumento de didatização da literatura, como se propõem a fazer muitas iniciativas e como sugere Mendonça (2010). Devemos considerar questionamentos acerca do papel e da representação do leitor, como este é constituído e em que momento este se relaciona com o texto em quadrinhos como um instrumento mediador da literatura, da imagem, ou da imagem interpretada como texto. Esta forma de representação textual-imagética, a exemplo de toda a sua trajetória histórica, não está confinada apenas a um plano de entretenimento, mas também a expressões de adaptação literária, estética e artística como apresentada neste artigo.

É possível, a partir de um diálogo entre essas duas formas de representação, o texto e a imagem, estabelecer questionamentos acerca dos paradigmas circunscritos às várias formas de expressão narrativa. Da forma semelhante à arte cinematográfica, que em seu início não gozava da mesma reputação que hoje possui, acusada por muitos de representar a morte do texto escrito, e igualmente subjugada como uma forma de expressão artística, as HQs hoje ainda padecem com um posicionamento semelhante. Por fim, é importante que a partir de um olhar aproximado para que favoreça uma reflexão mais ativa acerca das dimensões literárias das HQs e como estas não devem apenas estar centradas em um processo de percepção do texto na imagem, mas como uma percepção estética do texto como literatura e como tradução. 
DA SILVA, F. - Literatura e quadrinhos - adaptações de Edgar Allan Poe

\section{Referências bibliográficas}

Crandall, R. The Tell-tale Heart. Creepy. EUA: Dark Horse Comics, 1965.

CIRne, M. Quadrinhos, Sedução e Paixão. Petrópolis: Vozes, 2000.

Corben, R.; MARgopoulos, R. Edgar Alan Poe's Haunt of horror, n. 1. Marvel, 2006.

CoRben, R.; MARgopoulos, R. Edgar Alan Poe's Haunt of horror, n. 2. Marvel, 2006.

COSTA, S. R. Dicionário de gêneros textuais. Belo Horizonte: Editora Autêntica, 2009.

EISNER, W. Quadrinhos e arte sequencial. São Paulo: Martins Fontes, 1989.

HIDAYAT, R. S.; Zpalanzani, A.From novel into comic: a case of semiotic translation.TransCon Proceedings, 2011.

KRESS, G.; LeEUWEN, T. V. Reading images. The grammar of visual design. Londres: Routledge, 2006.

MCCLoud, S. Desvendando os quadrinhos. São Paulo: Makron Books, 1995.

MCCLOUd, S. Scott McCloud on comics. Disponível em: www.ted.com/talks/scott_mccloud_on_comics.html. Acesso em: 15 nov. 2012.

MendonçA, M. Ciência em quadrinho. Recife: Bagaço, 2010.

MUANIS, F. Imagem, cinema e quadrinhos: linguagens e discursos de cotidiano. 2006. Disponívelem: www.eca.usp.br/caligrama/n_4/05_FelipeMuanis.pdf

Pereira, N. M. Book Illustration as (Intersemiotic) Translation: Pictures Translating Words*. Revista Érudit. Canadá, 2012.

Sutton, T. The Fall of the House of Usher. Eerie. EUA, Warren, 1969.

Royal, D. P. Sequential Poe-try: Recent Graphic Narrative Adaptations of Poe. Poe Studies/Dark Romanticism, 2008. 